\title{
The sphingosine-1-phosphate transporter Spns2 expressed on endothelial cells regulates lymphocyte trafficking in mice
}

Shigetomo Fukuhara, ${ }^{1}$ Szandor Simmons, ${ }^{2,3}$ Shunsuke Kawamura, 2,3 Asuka Inoue,4

Yasuko Orba, 5 Takeshi Tokudome, ${ }^{6}$ Yuji Sunden, 7 Yuji Arai, ${ }^{8}$ Kazumasa Moriwaki,9

Junji Ishida, ${ }^{10}$ Akiyoshi Uemura, ${ }^{9}$ Hiroshi Kiyonari, ${ }^{11}$ Takaya Abe, ${ }^{11}$ Akiyoshi Fukamizu, ${ }^{10}$

Masanori Hirashima, ${ }^{9}$ Hirofumi Sawa, ${ }^{5}$ Junken Aoki, ${ }^{4}$ Masaru Ishii,2,3 and Naoki Mochizuki

1Department of Cell Biology, National Cerebral and Cardiovascular Center Research Institute, Osaka, Japan. '2Laboratory of Cellular Dynamics,

World Premier International Research Center-Immunology Frontier Research Center, Osaka University, Osaka, Japan. 3Japan Science and Technology,

Core Research for Evolutional Science and Technology (CREST), Tokyo, Japan. ${ }^{4}$ Laboratory of Molecular and Cellular Biochemistry,

Graduate School of Pharmaceutical Sciences, Tohoku University, Miyagi, Japan. ${ }^{5}$ Department of Molecular Pathobiology,

Hokkaido University Research Center for Zoonosis Control, Sapporo, Japan. ${ }^{6}$ Department of Biochemistry,

National Cerebral and Cardiovascular Center Research Institute, Osaka, Japan. ${ }^{7}$ Laboratory of Comparative Pathology,

Hokkaido University School of Veterinary Medicine, Sapporo, Japan. ${ }^{8}$ Department of Molecular Biology,

National Cerebral and Cardiovascular Center Research Institute, Osaka, Japan. 9Division of Vascular Biology, Department of Physiology and Cell Biology, Kobe University Graduate School of Medicine, Hyogo, Japan. ${ }^{10}$ Life Science Center, Tsukuba Advanced Research Alliance, University of Tsukuba, Ibaraki, Japan, and Graduate School of Life and Environmental Sciences, University of Tsukuba, Ibaraki, Japan.

${ }^{11}$ Laboratory for Animal Resources and Genetic Engineering, RIKEN Center for Developmental Biology, Hyogo, Japan.

\begin{abstract}
The bioactive lysophospholipid mediator sphingosine-1-phosphate (S1P) promotes the egress of newly formed $T$ cells from the thymus and the release of immature $B$ cells from the bone marrow. It has remained unclear, however, where and how S1P is released. Here, we show that in mice, the S1P transporter spinster homolog 2 (Spns2) is responsible for the egress of mature $T$ cells and immature $B$ cells from the thymus and bone marrow, respectively. Global Spns2-KO mice exhibited marked accumulation of mature $\mathrm{T}$ cells in thymi and decreased numbers of peripheral $\mathrm{T}$ cells in blood and secondary lymphoid organs. Mature recirculating B cells were reduced in frequency in the bone marrow as well as in blood and secondary lymphoid organs. Bone marrow reconstitution studies revealed that Spns2 was not involved in S1P release from blood cells and suggested a role for Spns2 in other cells. Consistent with these data, endothelia-specific deletion of Spns 2 resulted in defects of lymphocyte egress similar to those observed in the global Spns2-KO mice. These data suggest that Spns2 functions in ECs to establish the $\mathrm{S} 1 \mathrm{P}$ gradient required for $\mathrm{T}$ and $\mathrm{B}$ cells to egress from their respective primary lymphoid organs. Furthermore, Spns2 could be a therapeutic target for a broad array of inflammatory and autoimmune diseases.
\end{abstract}

\section{Introduction}

Sphingosine-1-phosphate (S1P) is a bioactive lysophospholipid mediator that plays a crucial role in diverse physiological functions, such as lymphocyte trafficking, vascular development, and inflammation (1-5). S1P exerts biological functions mostly through activating cellsurface G protein-coupled receptors S1P1-S1P5, while intracellular $\mathrm{S} 1 \mathrm{P}$ is also known to act as a second messenger to regulate inflammation (6). It remains unclear how intracellular S1P is transported to the outside of the cells to activate S1P receptors expressed on the cells.

The activation of S1P1 signaling in lymphocytes by S1P has been shown to promote the egress of newly formed $\mathrm{T}$ cells from the thymus and that of mature $\mathrm{T}$ and $\mathrm{B}$ cells from secondary lymphoid organs such as spleen and lymph nodes (7-10). An immunosuppressive molecule, FTY720, produces peripheral lymphopenia by blocking the lymphocyte egress from the thymus and lymph nodes. Interestingly, FTY720 was found to elicit the immunosuppressive effect by functionally antagonizing the $\mathrm{S} 1 \mathrm{P} / \mathrm{S} 1 \mathrm{P} 1$ signaling pathway $(8,11-13)$. In fact, this compound has been recently approved by the United States Food and Drug Administration for treatment of autoimmune diseases (14). In addition, S1P/S1P1

Conflict of interest: The authors have declared that no conflict of interest exists. Citation for this article: J Clin Invest. 2012;122(4):1416-1426. doi:10.1172/JCI60746. receptor signals direct the release of immature $\mathrm{B}$ cells from the bone marrow to the peripheral blood $(15,16)$.

The concentration of S1P is abundant in circulatory fluids, such as blood and lymph $(\sim \mu \mathrm{M})$, whereas it is normally kept low in the lymphoid tissues $(\sim \mathrm{nM})$ by S1P-degrading enzymes that include lipid phosphate phosphatase $3(17,18)$. However, it has been suggested that this concentration difference of $\mathrm{S} 1 \mathrm{P}$ is required but not sufficient for lymphocyte egress from lymphoid tissues into the circulation (9), implying the significance of S1P gradient made in lymphoid tissues. Consistently, S1P produced by neural crest-derived perivascular cells is required for efficient $\mathrm{T}$ cell egress (19). Moreover, lymphatic ECs release S1P, which is necessary for lymphocyte egress from lymph nodes into lymph (20). However, it is still unclear how $B$ and $T$ cell egress from the primary lymphoid organs and which cells release S1P that promotes the egress of these cells.

$\mathrm{S} 1 \mathrm{P}$ is generated inside of the cell by phosphorylation of sphingosine in a reaction catalyzed by sphingosine kinase 1 and 2, 2 closely related isozymes, and is exported toward the outside of the cell to stimulate its cell-surface receptors $(21,22)$. Release of S1P is observed in a variety of cells, such as platelets, erythrocytes, mononuclear cells, neutrophils, mast cells, and ECs (3, 21-28). In vitro analyses have revealed that $\mathrm{ABC}$ transporters mediate $\mathrm{S} 1 \mathrm{P}$ release in several types of cells, such as mast cells, erythrocytes, platelets, breast cancer cells, and 

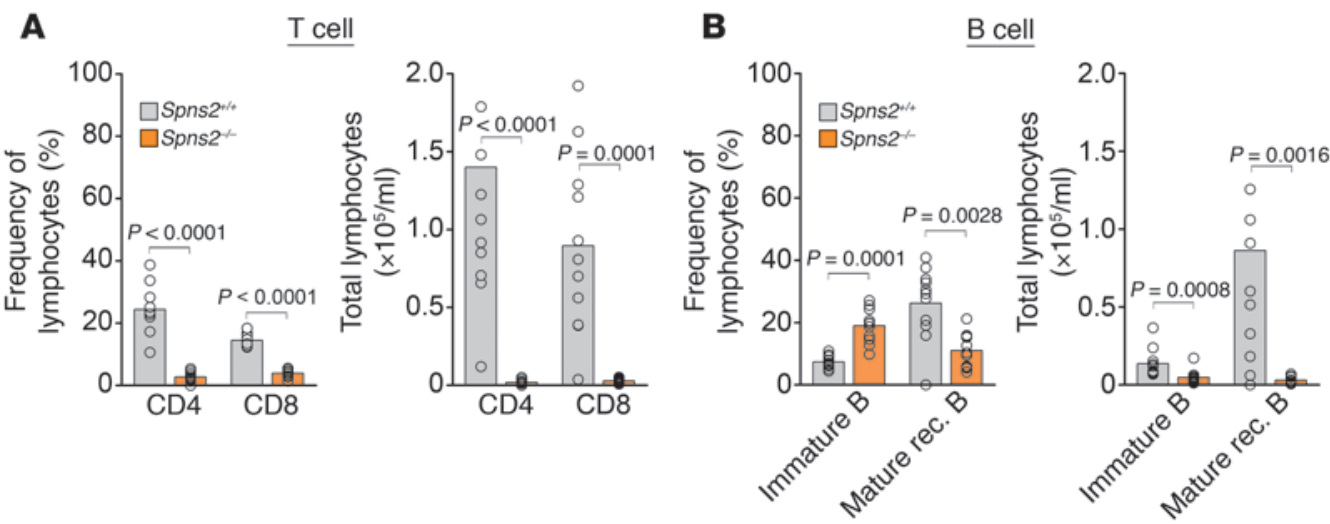

\section{Figure 1}

Mature $\mathrm{T}$ and recirculating mature B lymphocytes are remarkably reduced in the peripheral blood of Spns2--- mice. (A and B) Flow cytometric anal-

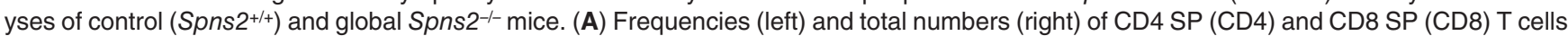
in peripheral blood are shown $(n=11)$. (B) Frequencies (left) and total numbers (right) of immature B cells $\left(\mathrm{CD}^{1} 9^{+} \mathrm{CD}^{2} 3^{-} \mathrm{lgD}-\lg \mathrm{M}^{+}\right.$, immature $\left.\mathrm{B}\right)$ and mature recirculating $\mathrm{B}$ cells $\left(\mathrm{CD} 19^{+} \mathrm{CD} 23^{+} \mathrm{IgD} \mathrm{D}^{+}\right.$, Mature rec. $\left.\mathrm{B}\right)$ in peripheral blood are shown $(n=11)$. In $\mathbf{A}$ and $\mathbf{B}$, bars and circles indicate averages and values for individual mice, respectively.

astrocytes $(24,29-32)$. We and others have identified the S1P transporter spinster homolog 2 (Spns2) as an S1P transporter in zebra fish $(33,34)$. However, the physiological functions of Spns 2 in mammals remain totally unknown. Furthermore, S1P transporters responsible for S1P-mediated lymphocyte trafficking have not been identified.

In the present study, we investigated the importance of Spns2 in lymphocyte trafficking by analyzing the Spns2-deficient mice and found that Spns2 is responsible for egress of mature T cells and immature B cells from thymus and bone marrow, respectively. We further revealed, by performing bone marrow reconstitution studies and by analyzing mice with conditional deletion of Spns2 in ECs, that ECs release S1P through Spns2, thereby promoting lymphocyte egress from both thymus and bone marrow.

\section{Results}

Spns2 is essential for trafficking of both $T$ and $B$ cells. To address the physiological functions of Spns 2 in mammals, we generated global Spns2-KO (Spns $\left.2^{-/-}\right)$mice by crossing Spns $2^{f / f}$ mice, in which exon 2 of the Spns2 gene is flanked with loxP sites, with mice expressing Cre recombinase under the control of cytomegalovirus promoter (Supplemental Figure 1; supplemental material available online with this article; doi:10.1172/JCI60746DS1). RT-PCR analyses of the RNA extracted from the lungs of WT and Spns $2^{-/-}$mice revealed that Spns $2^{-/-}$mice express a mutant mRNA transcript lacking exon 2derived sequence encoding aa 124-145 of WT Spns2 (Supplemental Figure 2, A and B). This Spns2 mutant protein failed to localize at the plasma membrane and lost the ability to export S1P (Supplemental Figure 2, C and D). Thus, we conclude that Spns $2^{-/-}$mice are indeed functionally disrupted for Spns2.

Spns $2^{-/-}$mice develop normally, survive to adulthood, and are fertile, although they exhibited symblepharon to a greater or lesser extent (Supplemental Figure 3). In addition, blood biochemical examination revealed no significant differences between WT and Spns $2^{-/-}$mice (Supplemental Figure 4). Notably, hematological analysis showed a significant decrease in white blood cell count in Spns $2^{-1-}$ mice compared with control mice, although there were no differences in the other hematological parameters, such as red blood cells, platelets, hemoglobin, hematocrit, mean corpuscular volume, mean corpuscular hemoglobin, and mean corpuscular hemoglobin concentration (Supplemental Figure 5), implying the role of Spns2 in lymphocyte trafficking.

It should be noted that the number and proportion of mature CD4 and CD8 single-positive (SP) T cells was dramatically reduced in the blood of Spns $2^{-/-}$mice (Figure $1 \mathrm{~A}$ and Supplemental Figure $6 \mathrm{~A})$. In addition, immature $\mathrm{B}$ cells $\left(\mathrm{CD} 19^{+} \mathrm{CD} 23-\mathrm{IgD}^{-} \mathrm{IgM}^{+}\right)$and mature recirculating $\mathrm{B}$ cells $\left(\mathrm{CD} 19^{+} \mathrm{CD} 23^{+} \mathrm{IgD}^{+}\right)$were decreased

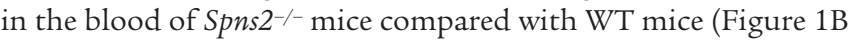
and Supplemental Figure 6B). These findings suggest that Spns2 is involved in trafficking of both $\mathrm{T}$ and $\mathrm{B}$ lymphocytes.

Spns 2 regulates $T$ cell egress from the thymus into blood. To study the cause of the decrease in mature $\mathrm{T}$ lymphocytes in the blood of Spns $2^{-/}$mice, we examined the thymus where T lymphocytes develop and from which they egress into blood. Spns2 $2^{-/-}$mice exhibited normal thymus structures (Supplemental Figure 7). The numbers and proportions of mature CD4 and CD8 SP T cells in the thymi of Spns $2^{-1-}$ mice were increased compared with those of WT mice, although there was no significant change in the number of immature CD4/CD8 double-positive (DP) T cells and CD4/CD8 doublenegative (DN) progenitor thymocytes (Figure 2, A and B). These data suggest a significant role for Spns 2 in modulating the egress of mature $\mathrm{T}$ cells from the thymus into the blood.

During final maturation of CD4 and CD8 SP T cells in the medulla of the thymus, they downregulate CD69, upregulate S1P1 and CD62L, and consequently migrate out of the thymus in response to S1P (35-38). Thus, we examined the semi-mature (CD69+CD62 $\left.\mathrm{L}^{\mathrm{lo} /-}\right)$ and fully mature $\left(\mathrm{CD} 69^{\mathrm{lo} /-} \mathrm{CD} 62 \mathrm{~L}^{+}\right) \mathrm{SP}$ T cells in the thymi of Spns $2^{-/-}$ mice. The proportion of fully mature SP T cells was increased in comparison with that of WT mice, while the relative amount of semimature SP T cells was decreased (Supplemental Figure 8, A and B). In addition, the cell-surface expression of CD69 on the fully mature SP T cells was slightly higher in Spns $2^{-/-}$mice than in WT mice (Supplemental Figure 8C). Since S1P is suggested to be required for full CD69 downregulation during final maturation of SP thymocytes $(8,36,39)$, this may be due to a decreased release of S1P in thymus of Spns $2^{-1-}$ mice. These results indicate that Spns2 is involved in the release of $\mathrm{S} 1 \mathrm{P}$ required for $\mathrm{T}$ cell egress from the thymus into the blood. 
A

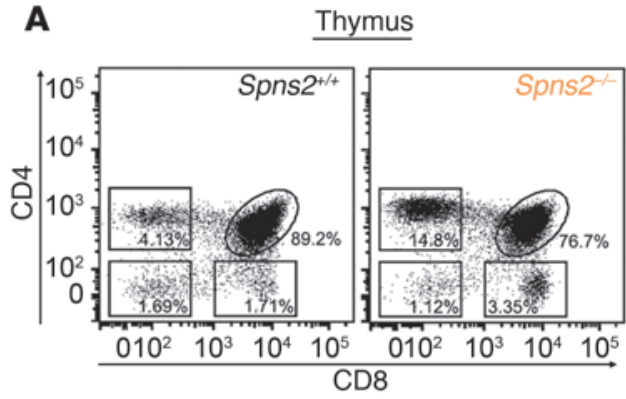

C

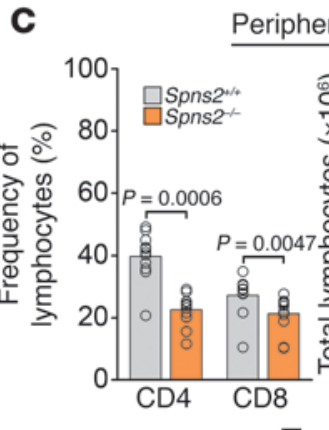

B

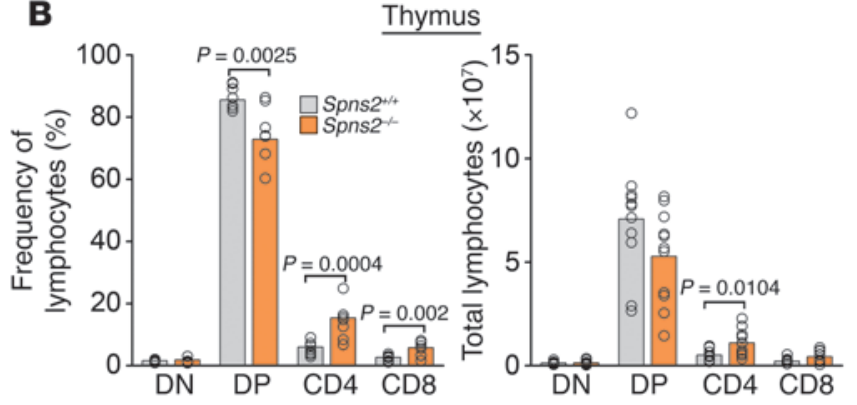

D

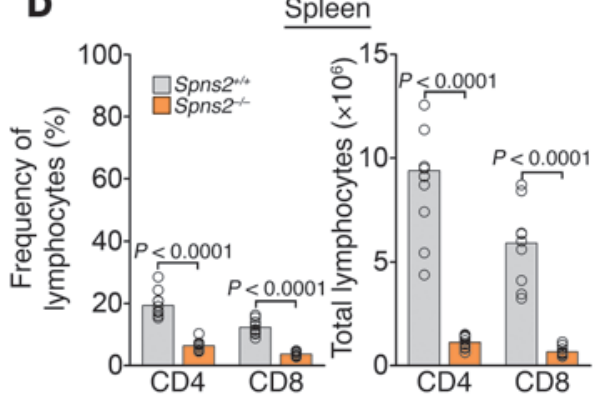

Spns2-

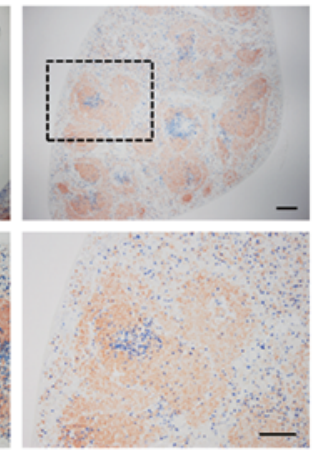

Figure 2

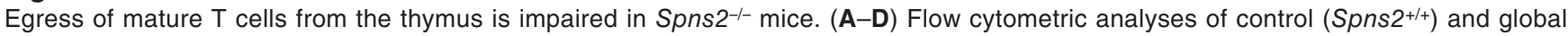
Spns2 $2^{-1-}$ mice. (A) A representative flow cytometric analysis of T cells in the thymus. The numbers represent the percentages of CD4 SP, CD8 $\mathrm{SP}, \mathrm{CD} 4 / \mathrm{CD} 8 \mathrm{DP} T$ cells, and CD4/CD8 DN thymocytes. (B) Frequencies (left) and total numbers (right) of CD4/CD8 DN (DN), CD4/CD8 DP (DP), CD4 SP (CD4) and CD8 SP (CD8) thymocytes and T cells are shown $(n=11)$. (C) Frequencies and numbers of CD4 SP (CD4) and CD8 SP (CD8) T cells in peripheral lymph nodes are shown $(n=11)$. (D) Frequencies and numbers of CD4 SP (CD4) and CD8 SP (CD8) T cells in spleens are shown $(n=11)$. In $\mathbf{B}-\mathbf{D}$, bars and circles indicate averages and values for individual mice, respectively. (E) Spleen sections from control $\left(\right.$ Spns $\left.2^{+/+}\right)$or Spns2 $2^{-/}$mice, stained to detect $\mathrm{CD}^{+} \mathrm{T}$ cells (blue) and B220+ B cells (red). The boxed areas of upper panels are enlarged in lower panels. Scale bars: $200 \mu \mathrm{m}$ (top row); $50 \mu \mathrm{m}$ (bottom row).

To assess the possibility that lack of mature T cells in the blood of Spns $2^{-1-}$ mice is related to their accumulation in other secondary lymphoid tissues, we further examined mature SP T lymphocytes in peripheral lymph nodes and in the spleen. In contrast with the accumulation of mature $T$ cells in the thymus, the numbers and proportions of mature CD4 and CD8 SP T cells were dramatically reduced in peripheral lymph nodes and in the spleen of Spns2mice, although their structures were normal (Figure 2, C-E, and Supplemental Figure 7). These results show that a decrease in the number of mature T cells in the peripheral blood of Spns $2^{-1-}$ mice is a consequence of impaired $\mathrm{T}$ cell egress from the thymus, but not due to the accumulation in the secondary lymphoid organs.

Spns 2 regulates egress of immature $B$ cells from the bone marrow into the blood. In the late stage of B cell development in the bone marrow, newly generated immature $\mathrm{B}$ cells are exported into the peripheral blood in an S1P/S1P1 signal-dependent manner $(15,16)$. The immature B cells subsequently undergo maturation in the secondary lymphoid tissues and migrate back to the bone marrow through the blood (recirculating mature B cells). To explore the cause of remarkable reduction of recirculating mature B lymphocytes in the peripheral blood of Spns2 $2^{-/-}$ mice, we examined the number and proportion of the lymphocytes at different developmental stages. The numbers and frequencies of mature recirculating B cells $\left(\mathrm{B} 220^{\text {hi }} \operatorname{IgM}^{+}\right.$or $\left.\mathrm{CD} 19^{+} \operatorname{IgM}{ }^{+} \operatorname{IgD}{ }^{+}\right)$were significantly reduced in the bone marrow of Spns $2^{-1-}$ mice compared with that of control mice (Figure 3, A and B, and Supplemental Figure 9). However, the number of pro-/pre-B cells $\left(\mathrm{B}^{2} 20^{+} \mathrm{IgM}^{-}\right)$and immature B cells $\left(\mathrm{B} 220^{\mathrm{lo}} \mathrm{IgM}^{+}\right.$or $\left.\mathrm{CD}^{1} 9^{+} \mathrm{IgM}^{+} \mathrm{IgD}^{-}\right)$was normal in the bone marrow of Spns2 $2^{--}$mice, although their frequencies were slightly 
A

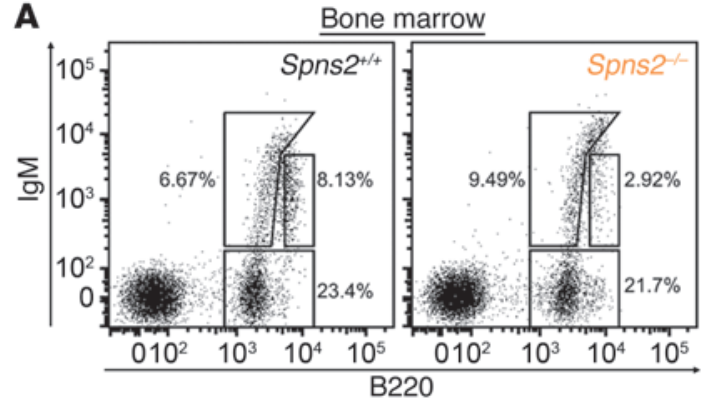

B

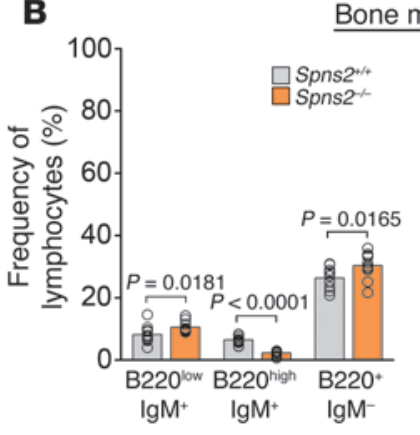

Bone marrow

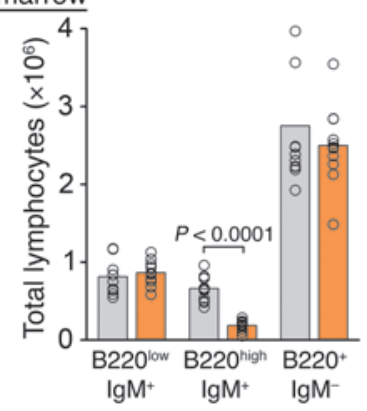

C

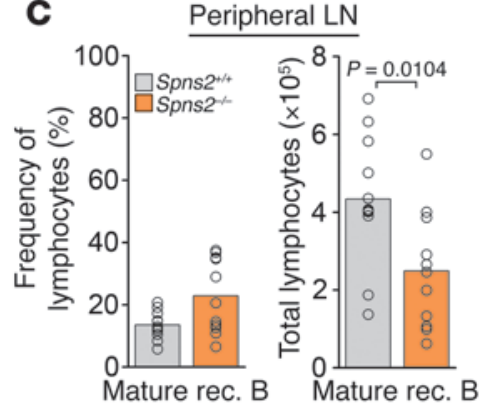

D

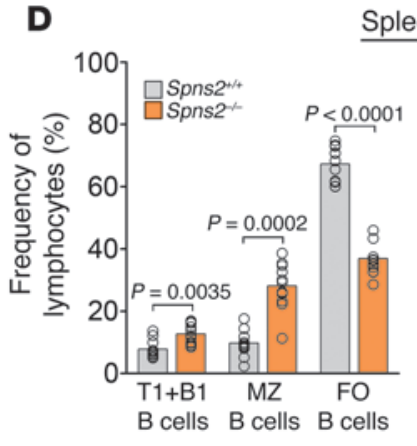

Spleen

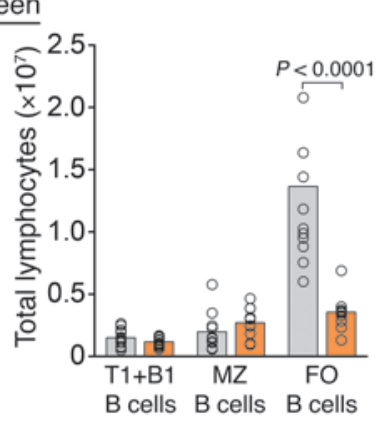

\section{Figure 3}

Immature B cell egress from bone marrow is impaired in Spns2 $2^{-/-}$mice. (A-D) Flow cytometric analysis of B cells in control (Spns2+/+) and Spns2 ${ }^{-1-}$ mice. (A) A representative flow cytometric analysis of progenitor B (B220+lgM-), immature B $\left(\mathrm{B}^{-} 20^{\mathrm{lo}} \mathrm{IgM}^{+}\right)$and mature recirculating $B$ cells $\left(\mathrm{B} 220^{\text {hil }} \mathrm{gM}^{+}\right)$in the bone marrow cavity. Numbers indicate the percentages of IgM- and B220-expressing cells of total lymphocytes. (B) Frequencies (left) and total numbers of pro-/pre-B cells $\left(\mathrm{B}^{2} 20^{+} \operatorname{lgM} \mathrm{M}^{-}\right)$, immature $B$ cells $\left(\mathrm{B}^{2} 20^{\circ} \mathrm{IgM}^{+}\right)$, and mature recirculating $B$ cells $\left(\mathrm{B}_{22} \mathrm{~h}^{\mathrm{hi}} \mathrm{gM}^{+}\right)$defined as in $\mathrm{A}$ are shown $(n=11)$. (C) Frequencies (left) and numbers (right) of mature recirculating $\mathrm{B}$ (mature rec. B) cells

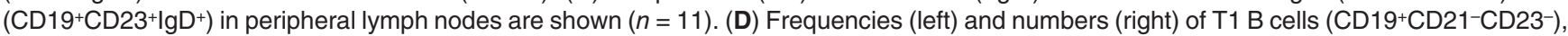
$\mathrm{MZ}\left(\mathrm{CD} 19^{+} \mathrm{CD} 21^{+} \mathrm{CD} 23^{\circ}\right)$, and follicular B cells $\left.(\mathrm{FO}) \mathrm{CD} 19+\mathrm{CD} 21^{10} \mathrm{CD} 23^{+}\right)$in spleens are shown $(n=11)$. In B-D, bars and circles indicate averages and values for individual mice, respectively.

higher than those in control mice, probably due to the reduction of mature recirculating B cell count (Figure 3, A and B, and Supplemental Figure 9). Together with the evidence for the decreased number of immature B cells in the peripheral blood of Spns $2^{-/-}$mice (Figure 1B), these results suggest that the egress of immature $B$ cells from the bone marrow is impaired in Spns $2^{-/-}$mice.

To further confirm this conclusion, we examined the number and proportion of B lymphocytes in the secondary lymphoid organs. In the peripheral lymph nodes, the number of mature B cells was reduced in Spns2 $2^{-1-}$ mice, although the frequency of mature B cells was not different from that in control mice (Figure 3C). In the spleen, the numbers and proportions of follicular B cells were significantly decreased in Spns $2^{-1-}$ mice compared with those of control mice, although there was no difference in the number of marginal zone (MZ) and transitional type 1 (T1) and B1 B cells between control and Spns $2^{-/-}$mice (Figure 3D). These results reveal that the decrease in mature recirculating B cells in the peripheral blood of Spns $2^{-1-}$ mice is not due to their accumulation in the secondary lymphoid organs, although it remains unclear whether Spns2 is involved in the egress of B lymphocytes from the secondary lymphoid organs. Therefore, we conclude that Spns2 is required for the egress of immature B cells from the bone marrow into the blood.

Spns 2 is not involved in S1P release from blood cells. Which cells expressing Spns2 are responsible for releasing S1P necessary for lymphocyte trafficking? Blood cells, especially erythrocytes, are known to produce S1P, thereby contributing to high plasma S1P concentration
(9, 23-26). Thus, we first investigated whether Spns2 is involved in $\mathrm{S} 1 \mathrm{P}$ release from blood cells. In Spns $2^{-/-}$mice, plasma S1P levels were reduced to $54 \%$ of those in control mice $(0.39 \pm 0.03 \mu \mathrm{M}$ in control mice; $0.21 \pm 0.01 \mu \mathrm{M}$ in Spns $2^{-/-}$mice), although plasma sphingosine and glycerolysophospholipids of Spns2 $2^{-/-}$mice were comparable to those in control mice (Figure 4, A-H). Most of the plasma S1P is known to be associated with HDL and albumin (40-42). Consistent with the reduced concentration of plasma S1P in Spns2-/- mice, the amount of S1P associated with HDL and albumin was lower in Spns $2^{-1-}$ mice than in WT mice (Supplemental Figure 10).

To further clarify whether the reduction of plasma S1P concentration in Spns $2^{-/-}$mice is attributed to the decreased S1P release from blood cells, we examined the secretion of S1P from blood cells isolated from either control or Spns $2^{-/-}$mice. S1P release from blood cells occurred in Spns $2^{-/-}$mice to an extent similar to that in control mice (Figure 5A). This S1P release was not caused by membrane damage, since no release was observed when the cells were incubated at $4^{\circ} \mathrm{C}$ (Figure 5A), as previously reported (27). These results suggest that Spns 2 is not involved in the release of S1P from blood cells. To further confirm this conclusion, we performed bone marrow reconstitution studies (Supplemental Figure 11). Reconstitution of irradiated Spns2 $2^{-/-}$ mice with WT bone marrow did not restore the reduced concentration of plasma S1P (Figure 5B). Furthermore, Spns $2^{-1-}$ mice reconstituted with WT bone marrow still exhibited accumulation of mature SP T lymphocytes in the thymus and reduction of mature recirculating B cells in the bone marrow in comparison with WT mice (Figure 5, 

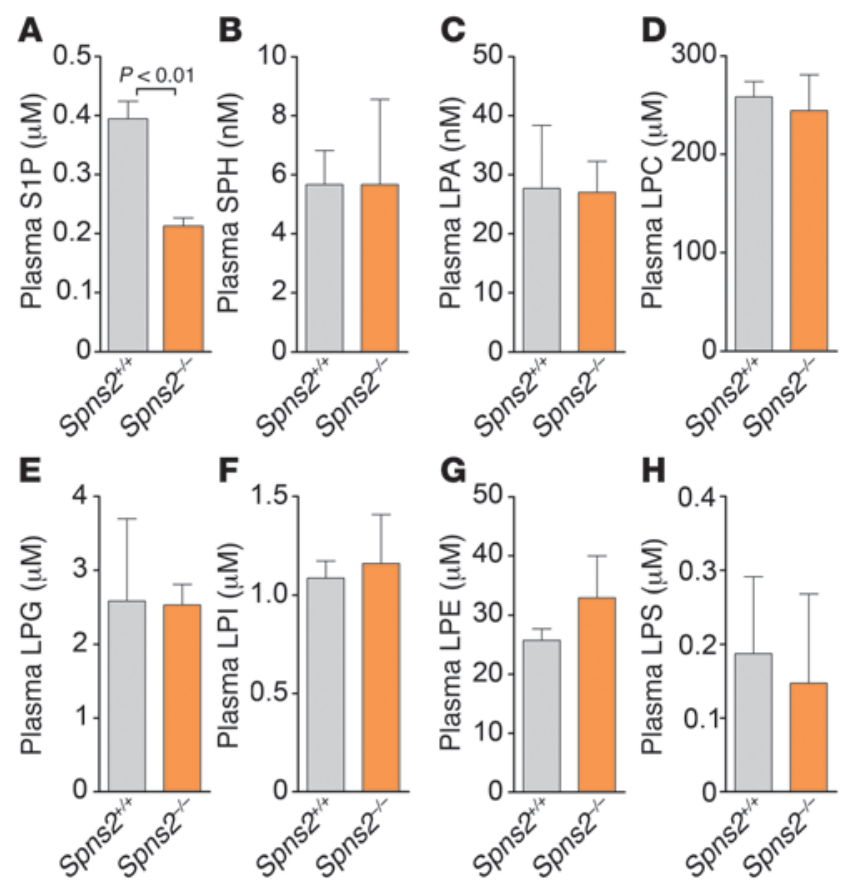

Figure 4

Plasma S1P concentration is reduced in Spns2 $2^{-/-}$mice. (A-H) Plasma concentrations of S1P (A), sphingosine (SPH) (B), LPA (C), LPC (D), LPG (E), LPI (F), LPE (G), and LPS (H) in control (Spns2 $\left.2^{+/+}\right)$or Spns2 $2^{-/}$ mice. Data are shown as mean $\pm \operatorname{SD}(n=3-5)$.

C and D). These findings indicate that cells other than blood cells expressing Spns2 secrete S1P to control lymphocyte trafficking.

$S p n s 2$ mediates $S 1 P$ release from ECs. Cultured vascular ECs produce S1P in vitro $(43,44)$, although S1P release from vascular ECs has not been confirmed in vivo. Another type of EC, lymphatic ECs, secrete $\mathrm{S} 1 \mathrm{P}$ into lymph, thereby regulating lymphocyte egress from lymph nodes (20). Thus, we next investigated whether Spns2 is involved in the release of S1P from ECs. RT-PCR analyses revealed that Spns2 is expressed not only in lymphatic ECs, but also in several types of vascular ECs (Figure 6A). In addition, depletion of Spns 2 by siRNA resulted in the inhibition of S1P release from ECs (Figure 6, B and C). Furthermore, we investigated whether Spns 2 is expressed in ECs in vivo by performing in situ hybridization analyses. Spns 2 mRNA was clearly expressed on the ECs in the thymus (Figure 6D). Although it has been reported that pericytes covering thymic ECs release S1P to promote T cell egress from thymus (19), we could not detect expression of Spns 2 mRNA on the pericytes in the thymus (Figure 6D). Besides the thymus, expression of Spns 2 mRNA was also observed in the ECs of other tissues, such as heart, lung, and hypothalamus, but not in those of kidney and olfactory bulb (Supplemental Figure 12). These results suggest that ECs secrete S1P through Spns2. Hence, we hypothesized that S1P released from ECs via Spns2 is required for lymphocyte egress from primary lymphoid organs.

ECs regulate thymic egress by releasing S1P through Spns2. To address whether Spns2 functions in ECs to regulate lymphocyte trafficking, we tried to generate mice lacking Spns2 in ECs (Spns2-ECKO: Spns $2 f / f ;$ Tie2Cre) by crossing the Spns2f/f mice with the mice expressing Cre recombinase under the Tie2 promoter (Supplemental Figure 1). In Spns2-ECKO mice, plasma S1P concentration was decreased to the level observed in Spns $2^{-/-}$mice (Supplemental Fig- ure 13), indicating that ECs release S1P into plasma in an Spns2dependent manner. Spns2-ECKO mice develop normally without symblepharon formation that is observed in global Spns $2^{-1-}$ mice, suggesting that Spns2 acts as an S1P transporter not only in ECs but also in other types of cells.

We further investigated whether Spns 2 functions in ECs to promote $\mathrm{T}$ cell egress from the thymus by S1P. Compared with control mice, the proportion of mature CD4 and CD8 SP T cells was increased in the thymus of Spns2-ECKO mice, but to a lesser extent than that in Spns2 $2^{--}$mice (Figure $2 \mathrm{~A}$ and Figure $7 \mathrm{~A}$ ). In addition, the number and proportion of CD4 and CD8 SP T cells in Spns2-ECKO mice were dramatically decreased in the peripheral blood, spleen, and peripheral lymph nodes (Figure 7, B and C, and Supplemental Figure 14), suggesting an impaired thymic egress of mature T lymphocytes in Spns2ECKO mice into the peripheral lymphoid organs. The Tie2 promoter is active not only in ECs, but also in hematopoietic cells (45-47). To further confirm that the phenotype of Spns2-ECKO mice is attributed to the impaired function of Spns 2 in ECs, we performed bone marrow reconstitution experiments. Spns2-ECKO mice reconstituted with control bone marrow exhibited accumulation of mature CD4 and CD8 SP T cells in the thymus, and their deficiency in the peripheral blood compared with control mice reconstituted with control bone marrow (Supplemental Figure 15). These findings apparently reveal that S1P released from ECs through Spns2 is involved in the egress of mature T cells from the thymus into the blood.

ECs promote the egress of immature $B$ cells from the bone marrow by releasing S1P through Spns2. We further investigated the role of ECs in immature B cell egress from the bone marrow. As observed in Spns $2^{-1-}$ mice, the numbers and proportions of mature recirculating B cells, but not pro-/pre-B cells and immature B cells, were remarkably decreased in the bone marrow of Spns2-ECKO mice in comparison with control mice (Figure 8A and Supplemental Figure 16). Mature recirculating $B$ cells in the blood and peripheral lymph nodes of Spns2-ECKO mice were decreased (Figure 8B and Supplemental Figure 17). Furthermore, the numbers and frequencies of follicular B cells were significantly reduced in the spleen of Spns2ECKO mice compared with control mice (Figure 8C), although the number of MZ B cells in the spleen was comparable between WT and Spns2-ECKO mice. Unexpectedly, the spleens of Spns2-ECKO mice have increased numbers of T1 and B1 B cells compared with those of control mice. This result may imply a more complex role of Spns 2 in B cell trafficking that has to be tested in more detail in further experiments. Moreover, reconstitution of irradiated Spns2ECKO mice with control bone marrow did not restore reduction of mature recirculating $B$ cells in the bone marrow and peripheral blood (Supplemental Figure 18). These results demonstrate that $\mathrm{S} 1 \mathrm{P}$ released by ECs through Spns2 promotes the egress of immature B cells from the bone marrow into the blood.

\section{Discussion}

In the present study, we show for what we believe is the first time that Spns2 expressed on ECs is essential for lymphocyte egress from the primary lymphoid organs. By analyzing the Spns2-deficient mice, we found that Spns2 is an S1P transporter required for the egress of mature $T$ cells and immature $B$ cells from the thymus and the bone marrow, respectively, into the peripheral blood. In addition, by deleting Spns 2 in ECs and performing bone marrow reconstitution studies, we showed that Spns2 regulates S1P secretion in ECs, but not in blood cells, to promote lymphocyte egress from primary lymphoid organs. Therefore, the 

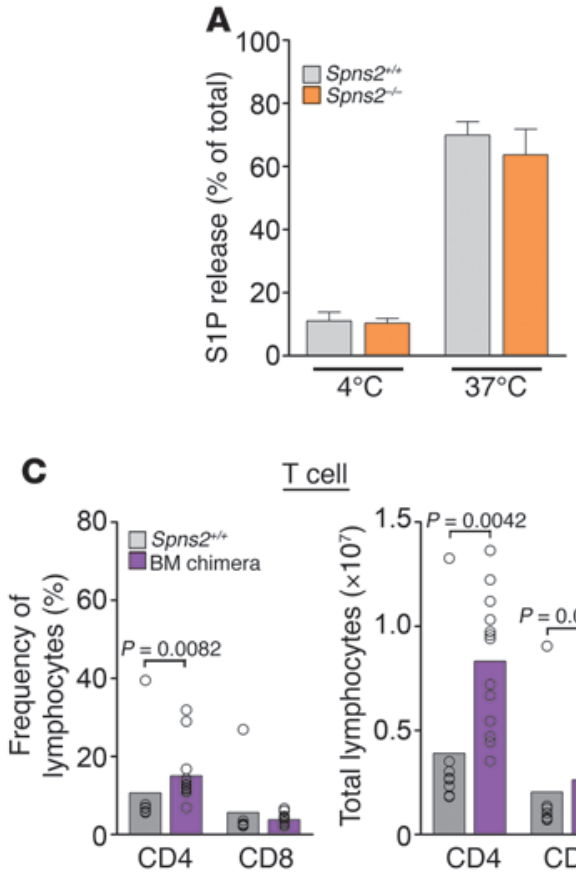

T cell
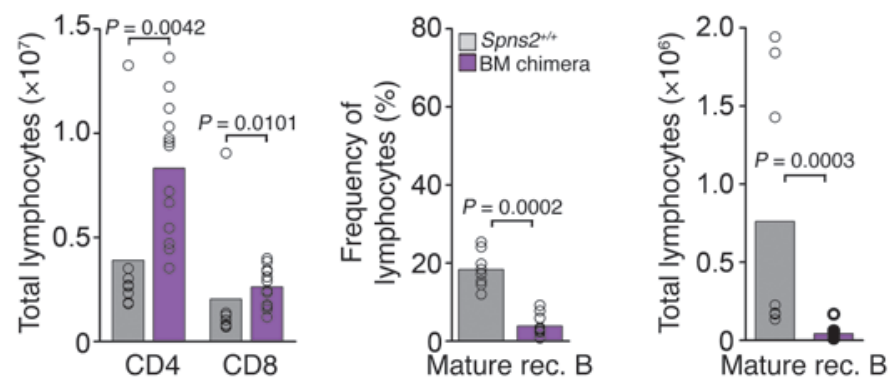

Figure 5

Spns2 is not involved in S1P release from blood cells. (A) Release of S1P by the blood cells isolated from control $\left(S p n s 2^{+/+}\right)$and Spns $2^{-/-}$mice. Cells were incubated at either $4^{\circ} \mathrm{C}$ or at $37^{\circ} \mathrm{C}$ for 90 minutes as indicated at the bottom. Data are expressed as a percentage of the total amount of S1P in the cells without incubation and shown as mean $\pm \operatorname{SD}(n=4)$. (B-D) Spns2 $2^{-/-}$mice were lethally irradiated and reconstituted with bone marrow from littermate control mice. (B) Plasma S1P concentrations of either Spns2 ${ }^{-/-}$mice (Pre) or of those reconstituted with WT bone marrow (Post) $(n=13)$. (C and D) Flow cytometric analyses of control $\left(S p n s 2^{+/+}\right)$and Spns2 $2^{--}$mice reconstituted with littermate control bone marrow (BM chimera). (C) Frequencies (left) and total numbers (right) of CD4 SP (CD4) and CD8 SP (CD8) T cells in the thymus are shown (Spns2 $2^{+/+}, n=8$; BM chimera, $n=13$ ). (D) Frequencies (left) and total numbers of mature recirculating B cells $\left(C D 19^{+} \operatorname{lgM} M^{+} \lg D^{+}\right)$in the bone marrow are shown $\left(\right.$ Spns2 $2^{+/+}, n=8$; BM chimera, $n=13$ ).

present study on Spns2 largely contributes to the understanding of S1P signaling, which is used in the egress of lymphocytes from primary lymphoid organs $(1,2,4,5)$.

Spns2 is the first S1P transporter functioning in mammals. Intracellularly generated S1P has to be transported out of the cell to stimulate its cell-surface receptors. Several lines of evidence obtained from in vitro studies have suggested the involvement of the ABC family of transporters in S1P release from several types of cells $(22,24,29-32)$. However, their biological significance in vivo has remained unclear. In this study, we demonstrate Spns 2 as a key $\mathrm{S} 1 \mathrm{P}$ transporter that regulates lymphocyte trafficking in mammals. Although Spns2 regulates lymphocyte trafficking by inducing the release of S1P from ECs, this transporter may also function in other cells, since symblepharon was observed in Spns $2^{-1-}$ mice, but not in Spns2-ECKO mice. On the other hand, Spns2 appears not to be the only transporter of S1P in mammals because plasma S1P levels were partially but not completely decreased in Spns $2^{-/-}$mice compared with control mice. Although blood cells, especially erythrocytes, are thought to be the major cellular source of S1P in plasma $(9,23,27)$, blood cells from Spns $2^{-/-}$mice still retained the ability to release S1P (Figure 5A). Thus, S1P release from blood cells appears to be mediated by S1P transporters other than Spns2. In addition, S1P transporters other than Spns2 might also be involved in the release of S1P required for vascular development, since Spns2 $2^{-/}$mice did side of blood vessels by S1P locally released from both ECs and pericytes, and possibly exit into the peripheral blood in response to high concentrations of plasma S1P. However, further studies are needed to confirm this hypothesis.

Spns2 expressed on ECs of the blood vessels is also essential for B cell egress from the bone marrow. Although recent reports reveal the role of S1P/S1P1 signaling in the egress of immature B cells from the bone marrow $(15,16)$, a cellular source of S1P involved in this process has not been identified. In Spns $2^{-/-}$mice, the number of mature recirculating $B$ cells was significantly decreased not only in the bone marrow but also in the blood, spleen, and peripheral lymph nodes, indicating a block in the egress of immature B cells from the bone marrow. Importantly, reconstitution of irradiated Spns $2^{-/-}$mice with WT bone marrow did not rescue the deficiency of mature recirculating B cells in the bone marrow. Furthermore, Spns2-ECKO mice also exhibited reduced numbers of mature recirculating $B$ cells in the bone marrow, peripheral blood, spleen, and peripheral lymph nodes, as observed in Spns2-/- mice. This phenotype was not rescued by reconstitution with control bone marrow. Thus, these results reveal for what we believe is the first time that ECs are the major cellular source of S1P necessary for the egress of immature B cells from the bone marrow. In the late stage of $\mathrm{B}$ cell development in the bone marrow, newly generated immature $B$ cells placed in the parenchyma are first recruited into the sinusoidal compartment and subsequently 


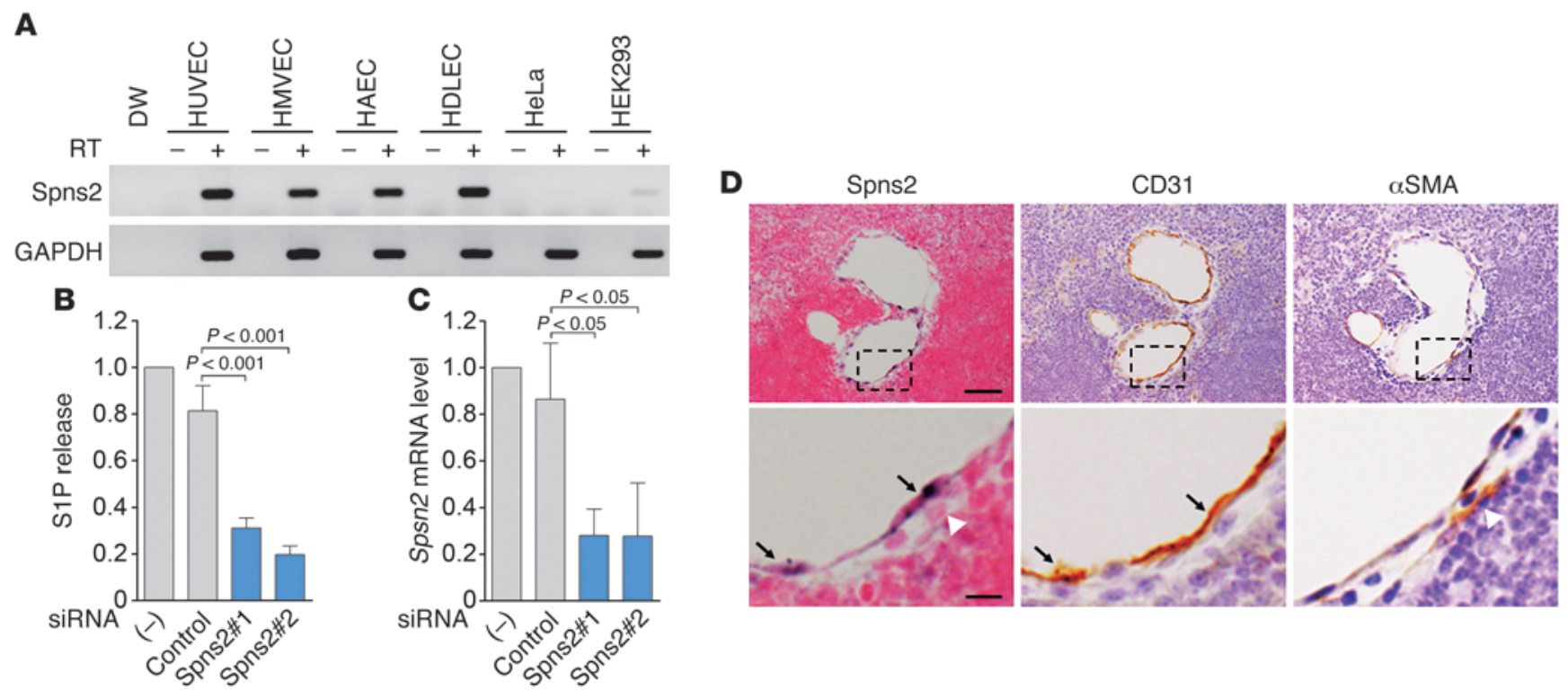

\section{Figure 6}

Spns2 is involved in S1P release from ECs. (A) Expression of Spns2 in ECs. RT-PCR analysis was performed to examine the expression of Spns2 in HUVECs, HMVECs, HAECs, HDLECs, HeLa, and HEK293 cells as indicated at the top. PCR was performed using specific primers for either Spns2 (upper panel) or GAPDH (lower panel). To verify the absence of contaminating genomic DNA, RT-PCR was also performed in the absence of reverse transcriptase (-). (B and C) S1P release from Spns2-depleted ECs. (B) Release of S1P by ECs transfected without (-) or with either control siRNA (control) or 2 independent siRNAs targeting Spns2 (Spns2\#1 and Spns2\#2). (C) Real-time RT-PCR analysis to assess the efficiency of siRNA-mediated Spns2 knockdown. In B and C, data are expressed relative to those observed in the untransfected cells and shown as mean \pm SD of 3 independent experiments. (D) In situ hybridization for Spns2 mRNA in thymus. Antisense probe was hybridized to thymus section (Spns2: purple). Serial sections were also stained with anti-CD31 (CD31: brown) and anti- $\alpha$-SMA (brown) antibodies to identify ECs and pericytes, respectively. The boxed areas of upper panels are enlarged in lower panels. Arrows and white arrowheads indicate ECs and pericytes, respectively. Scale bars: $50 \mu \mathrm{m}$ (upper panels); $10 \mu \mathrm{m}$ (lower panels).

exported into the peripheral blood (50-52). Sinusoidal entry of immature B cells is thought to be a key step in bone marrow egress. Recently, it has been reported that $\mathrm{S} 1 \mathrm{P} / \mathrm{S} 1 \mathrm{P} 1$ signaling promotes the movement of immature $B$ cells from parenchyma to sinusoid, thereby facilitating egress of immature $B$ cells from bone marrow $(15,16)$. Thus, bone marrow sinusoidal ECs may attract immature B cells from the parenchyma by producing S1P through Spns2 and thereby promoting the immature B cell egress into the peripheral blood.

The lymphocyte egress from secondary lymphoid organs such as lymph nodes and spleen also depends on S1P/S1P1 signaling. Pham et al. have recently reported that lymphatic ECs are an in vivo source of S1P required for lymphocyte egress from lymph nodes and Peyer patches (20). Since Spns2 is expressed not only in vascular ECs but also in lymphatic ECs, Spns2 may also regulate lymphocyte egress from lymph nodes by inducing the release of S1P from lymphatic ECs. However, to address this hypothesis, we need to analyze mice lacking Spns2 specifically in the lymphatic ECs because lymphocyte egress from primary lymphoid organs is severely impaired in global Spns2 $2^{-1}$ mice. It also remains elusive whether Spns 2 is involved in lymphocyte egress from spleen. Thus, this will be a subject for future studies.

In conclusion, we demonstrate that Spns2 is a key S1P transporter involved in lymphocyte trafficking and further indicate that vascular ECs are the major source of S1P in vivo responsible for lymphocyte egress from the thymus and the bone marrow. Thus, this study not only reveals the crucial role of Spns2 as an S1P transporter in mammals, but also contributes to our understanding of molecular mechanisms of S1P-mediated lymphocyte trafficking.
Since S1P signaling is profoundly involved in the inflammatory and autoimmune diseases, such as multiple sclerosis, psoriasis, asthma, and rheumatoid arthritis, as well as in transplantation, Spns2 can be a potential therapeutic target for these diseases.

\section{Methods}

Generation of Spns2fff mice. Spns2fff mice (acc. no. CDB0705K; http://www.cdb. riken.jp/arg/mutant\%20mice\%20list.html), in which exon 2 is flanked by 2 loxP sites, were generated (Supplemental Figure 1A). TT2 ES cells derived from an F1 hybrid of C57BL/6 and CBA mice (53) were transfected with the targeting vector, selected in the presence of G418, and screened for homologous recombination by PCR and Southern blotting. Two ES clones were introduced into host embryos to generate chimeric mice. Chimeric mice with a high ES cell contribution were bred with the CMV-Cre mice (C57BL/6 strain background) expressing Cre recombinase under the control of cytomegalovirus promoter to generate heterozygous Spns2 ${ }^{+/-}$mice (Supplemental Figure 1). Spns2 $2^{+-}$mice were intercrossed to obtain Spns2 $2^{-/-}$mice (75\% C57BL/6 and $25 \% \mathrm{CBA}$ genetic background). The chimeric mice were also crossed with the CMV-Flp mice (C57BL/6 strain background) expressing Flp recombinase under the control of cytomegalovirus early enhancer/chicken $\beta$-actin promoter to remove the PKG-Neo-pA cassette, resulting in Spns2 floxed mice (Supplemental Figure 1). To inactivate the Spns2 gene in ECs, the Spns2 floxed mice were bred with Tie2-Cre mice (C57BL/6 strain background), which carry the Cre recombinase driven by the Tie2 promoter $(45,46)$ and were provided by T.N. Sato (Nara Institute of Science and Technology, Nara, Japan) and M. Yanagisawa (University of Texas Southwestern Medical Center, Dallas, Texas, USA) (Supplemental Figure 1). For confirmation of cor- 
A

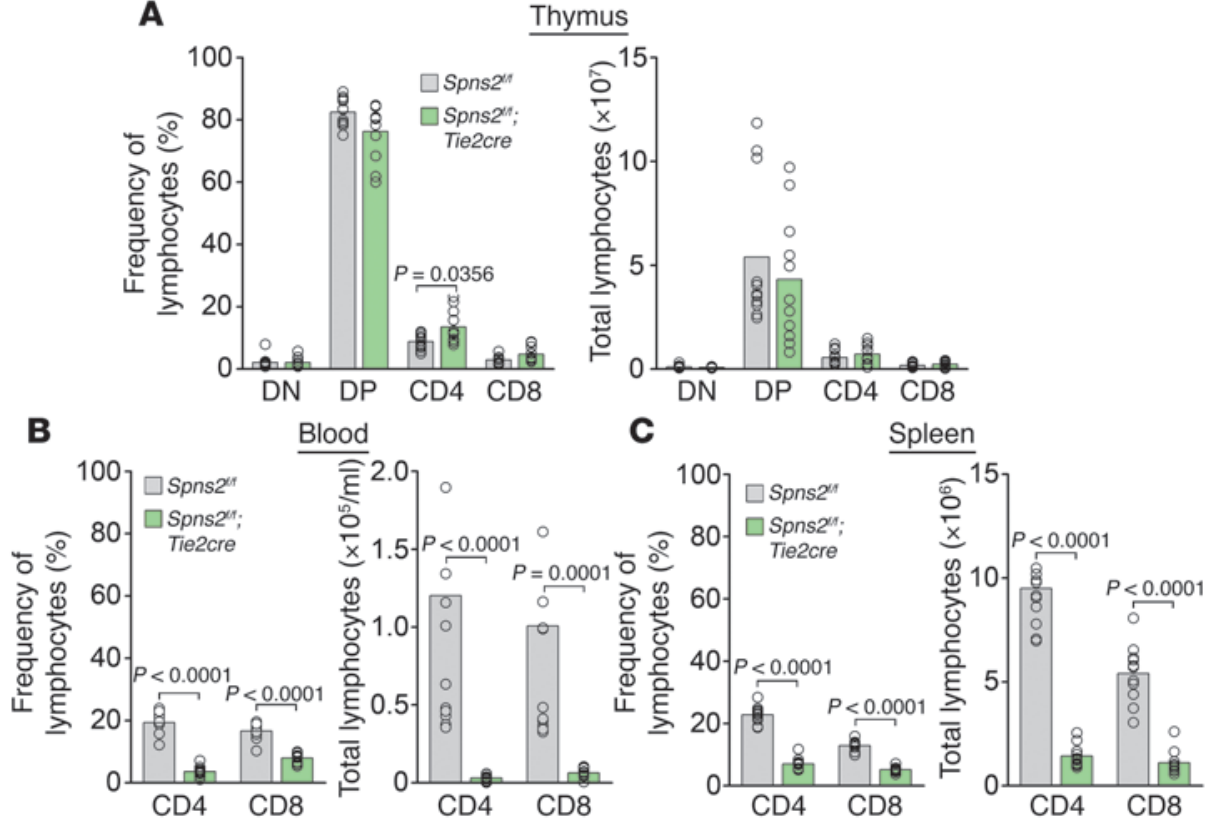

\section{Figure 7}

Spns2 expressed in ECs is required for mature $T$ cell egress from thymus. (A-C) Flow cytometric analyses of lymphocytes of control (Spns2 $2^{f / f}$ ) or Spns2-ECKO (Spns2t/f;Tie2Cre) mice. (A) Frequencies (left) and numbers (right) of CD4/CD8 DN (DN), CD4/CD8 DP (DP), CD4 SP (CD4), and CD8 SP (CD8) thymocytes and T cells in thymus are shown $(n=11)$. (B) Frequencies and numbers of CD4 SP (CD4) and CD8 SP (CD8) T cells in peripheral lymph nodes are shown $(n=11)$. (C) Frequencies and numbers of CD4 SP (CD4) and CD8 SP (CD8) T cells in spleens are shown $(n=11)$. In A-C, bars and circles indicate averages and values for individual mice, respectively. rect targeting, Southern blot analysis was performed with the probe located outside of the regions used in the targeting vector (Supplemental Figure 1). For the genotyping of mice, PCR was performed using a forward primer, 5'-AGGCTCATTTCATGGCTGAT-3', and a reverse primer, 5'-AGCCCTGTGCTCTCTGTTGT- $3^{\prime}$, producing products of 552-bp fragment for WT allele, 842-bp fragment for floxed allele, and 316-bp fragment for deleted allele. All mice were housed under specific pathogen-free conditions.

RT-PCR and real-time RT-PCR. To check the expression of Spns 2 mRNA in Spns $2^{-/}$mice, total RNA was extracted from the lungs using TRIzOL reagent (Invitrogen) and reverse transcribed by random hexamer primers using Superscript II (Invitrogen) according to the manufacturer's instructions. PCR amplification was carried out with the following primer sets: PCR1, 5'-AAGAGGTGCAGACGTTGTCC-3' and 5'-CCACAGCTGAGGATCACCTT-3', for exons 1-3 of the mouse Spns2; and PCR2, 5'-ATGATGTGCCTGGAATGC-3' and 5'-TCAGACTTTCACGGATGCAG-3', for complete coding sequence of mouse Spns2.

To determine the expression of Spns2 in ECs, RT-PCR was performed using the gene-specific primers for human SPNS2 (5'-ACTTTGGGGTCAAGGACCGA-3' and 5'-AATCACCTTCCTGTTGAAGCG-3'). Amplification of GAPDH was also performed using the gene-specific primers for human GAPDH (5'-ATGGGGAAGGTGAAGGTCG-3' and 5'-GGGGTCATTGATGGCAACAATA-3') in parallel as a control.

To assess the efficiency of siRNA-mediated knockdown of Spns2, total RNA was extracted from HUVECs transfected without or with either control siRNA or 2 independent siRNAs targeting Spns2 and subjected to quantitative real-time RT-PCR analysis using the QuantiFast SYBR Green RT-PCR Kit (QIAGEN) as described (54). For each reaction, 100 ng of total RNA was transcribed for 10 minutes at $50^{\circ} \mathrm{C}$, followed by a denaturation step at $95^{\circ} \mathrm{C}$ for 5 minutes, 40 cycles of 10 seconds at $95^{\circ} \mathrm{C}$, and 30 seconds at $60^{\circ} \mathrm{C}$. Fluorescence data were collected and analyzed using Mastercycler ep realplex (Eppendorf). For normalization, expression of human GAPDH was determined in parallel as an endogenous control. The gene-specific primers used to amplify human SPNS2 and GAPDH were the same as described above.

Cell culture, transfection, and siRNA-mediated gene silencing. HUVECs, human microvascular ECs (HMVECs), and human aortic ECs (HAECs) were purchased from Kurabo and maintained as described previously (55). Human dermal lymphatic ECs (HDLECs) were obtained from Lonza and maintained in EC growth medium EGM-2 (Lonza). HeLa and HEK293 cells were cultured in DMEM (Nissui) supplemented with $10 \%$ fetal bovine serum and antibiotics (100 $\mu \mathrm{g}$ of streptomycin/ml and $100 \mathrm{U}$ of penicillin/ml).

Stealth siRNAs targeted to human Spns2 (HSS151335 and HSS151336) were purchased from Invitrogen. As a control, siRNA duplexes with irrelevant sequences were used. HUVECs were transfected with $20 \mathrm{nM}$ siRNA duplexes using Lipofectamine RNAi MAX reagent (Invitrogen). After incubation for 48 hours, the cells were used for the experiments.

Detection of subcellular localization of GFP-tagged Spns2. cDNAs encoding WT and mutant Spns2 were amplified using cDNAs derived from the lungs of WT and Spns2-/- mice by RT-PCR, and cloned into pEGFP-N1 vector to construct the expression plasmids encoding WT and mutant Spns2 with a C-terminal GFP tag, respectively. HUVECs were transfected with the plasmid encoding either WT or mutant Spns2-GFP or with myristoylated GFP-encoding plasmid. GFP and phase contrast images were obtained using an IX81 inverted microscope (Olympus) equipped with a pE-1 LED excitation system (CoolLED).

S1P release from cultured cells. HEK293 cells were plated in 24-well plates $\left(5 \times 10^{4}\right.$ cells/well $)$, cultured for 24 hours, and transfected with the expression plasmids indicated in the legend of Supplemental Figure 2D using Lipofectamine 2000 reagent (Invitrogen). After incubation for 24 hours, cells were incubated in $250 \mu \mathrm{l}$ of serum-free DMEM containing $0.5 \%$ fatty acid-free bovine serum albumin, $10 \mathrm{mM}$ sodium glycerophosphate, $5 \mathrm{mM}$ sodium fluoride, and $1 \mathrm{mM}$ semicarbazide for 24 hours. To determine the role of Spns 2 in S1P release from ECs, HUVECs transfected without or with either control siRNA or 2 independent Spns 2 siRNAs were detached, replated in collagen-coated 24 -well plates $\left(2.5 \times 10^{5}\right.$ cells/well), and cultured for 12 hours. The cells were then washed twice with Medium 199 (Invitrogen) and incubated in $200 \mu \mathrm{l}$ of Medium 199 containing $20 \mathrm{mM}$ Hepes, pH 7.4, $10 \mathrm{mM}$ sodium glycerophosphate, $5 \mathrm{mM}$ sodium fluoride, $1 \mathrm{mM}$ semicarbazide, $0.5 \%$ fatty acid free bovine serum albumin, $40 \mathrm{ng} / \mathrm{ml}$ vascular endothelial growth factor, $40 \mathrm{ng} / \mathrm{ml}$ fibroblast growth factor- 2 , and $400 \mathrm{ng} / \mathrm{ml}$ angiopoietin- 1 for 12 hours. After incubation, conditioned medium was collected and centrifuged at $15,000 \mathrm{~g}$ for 5 minutes at $4^{\circ} \mathrm{C}$ to remove cell debris. S1P levels in the conditioned medium were determined as described below. 


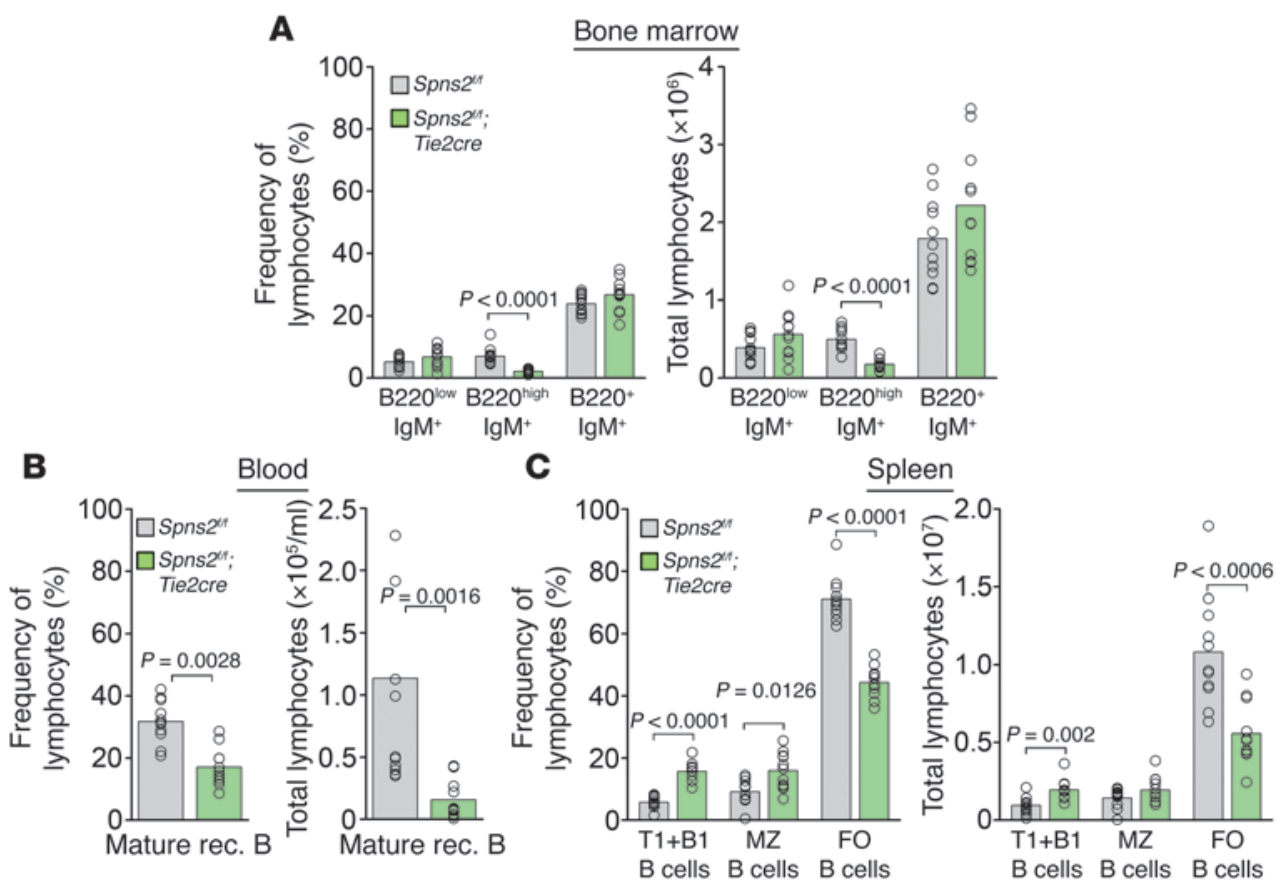

Figure 8

Spns2 expressed in ECs is required for immature B cell egress from bone marrow. (A-C) Flow cytometric analyses of lymphocytes of control $\left(S p n s 2^{f / f}\right)$ or Spns2-ECKO (Spns2 $2^{f / f}$;Tie2Cre) mice. (A) Frequencies (left) and numbers (right) of pro-/pre-B cells (B220+lgM-), immature B cells $\left(\mathrm{B}^{-2} \mathrm{O}^{\circ} \mathrm{logM}^{+}\right)$, and mature

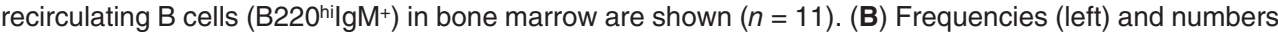
(right) of mature recirculating $B$ (Mature rec. B) cells $\left(C D 19^{+} C D 23^{+} \lg D^{+}\right)$in peripheral blood are shown $(n=11)$. (C) Frequencies (left) and numbers (right) of T1 and B1 B cells (T1+B1), MZ, and follicular B cells in spleens are shown $(n=11)$. T1 and B1 B cells, MZ B cells, and follicular B cells were phenotypically defined as described in the legend of Figure 3D. In A-C, bars and circles indicate averages and values for individual mice, respectively.

Quantification of S1P using LC-MS/MS. Quantification of S1P was performed according to previously described methods (56) with minor modifications. Briefly, plasma and conditioned medium were mixed and sonicated with 10-fold volume of methanol and an internal standard (C17-S1P). Similarly, $\mathrm{S} 1 \mathrm{P}$ extraction from cells was performed by homogenizing and sonicating cells in methanol. After centrifugation at $21,500 \mathrm{~g}$, the resulting supernatant was recovered and used for the LC-MS/MS analysis. Then $20 \mu \mathrm{l}$ of methanol extract was injected and separated by Nanospace LC (Shiseido) equipped with a C18 CAPCELL PAK ACR column $(1.5 \times 250 \mathrm{~mm}$; Shiseido), using a gradient of solvent $\mathrm{A}(5 \mathrm{mM}$ ammonium formate in water) and solvent $\mathrm{B}$ ( $5 \mathrm{mM}$ ammonium formate in $95 \%[\mathrm{v} / \mathrm{v}]$ acetonitrile). Elution was sequentially ionized with an ESI probe, and the parent ion $(\mathrm{m} / z$ 380.2) and the fragment ion $(m / z 264.2)$ were monitored in the positive mode by a Quantum Ultra Triple Quadrupole Mass Spectrometer (Thermo Fisher Scientific). Similarly, other lysophospholipids, including lysophosphatidic acid (LPA), lysophosphatidylcholine (LPC), lysophosphatidylethanolamine (LPE), lysophosphatidylglycerol (LPG), lysophosphatidylinositol (LPI), and lysophosphatidylserine (LPS), were extracted with methanol and analyzed by the LC-MS/MS system. For each lysophospholipid class, 12 acyl chains (14:0, 16:0, 16:1, 18:0, 18:1, 18:2, 18:3, 20:3, 20:4, 20:5, 22:5, and 22:6) were monitored.

For quantification of HDL- and albumin-bound S1P, mouse plasma was subjected to size-exclusion chromatography according to previously described methods (57) with some modifications. Briefly, $100 \mu$ l of plasma was loaded onto a Superose 12 column (GE Healthcare) using an ÄKTA Explorer System (GE Healthcare) and eluted with PBS at $0.25 \mathrm{ml} / \mathrm{min}$ at $4^{\circ} \mathrm{C}$. Fractions were collected every 2 minutes $(0.5 \mathrm{ml})$. S1P concentration in each fraction was determined by LC-MS/MS as described above.

Biochemical and hematological test of blood. Blood was collected from WT $\left(\right.$ Spns $\left.2^{+/+}, n=4\right)$ and Spns2 $2^{-/-}\left(\right.$Spns2 $2^{-/}$, $n=4)$ mice via the abdominal aorta under inhalation anesthesia (isoflurane) using EDTA as an anticoagulant. Blood biochemistry parameters (total protein, total bilirubin, aspartate aminotransferase, alanine aminotransferase, triglycerol, glucose, blood urea nitrogen, and albumin) were determined by using a blood biochemical analyzer, Fuji DRI-CHEM 3500V (Fuji Film). Hematology and blood clotting parameters (white blood cells, red blood cells, platelets, hemoglobin, hematocrit, mean corpuscular volume, mean corpuscular hemoglobin, and mean corpuscular hemoglobin concentration) were determined by using an XT-1800iv hematology analyzer (Sysmex).

Antibodies and flow cytometric analysis. Unless otherwise stated, all antimouse monoclonal antibodies were obtained from eBiosciences Inc. Antibodies used for cell-surface staining were PE-conjugated anti-CD19 (ebio1D3), anti-CD8 (53-6.7), and anti-CD23 (B3B4); FITC-conjugated anti-B220 (RA3-6B2), anti-CD19 (1D3) (BD Biosciences), anti-CD8 (53-6.7) and anti-CD69 (H1.2F3) (BD Biosciences); APC-conjugated anti-CD62L (MEL-14) (BioLegend); Pacific Blue-conjugated anti-IgD (11-26) and anti-CD4 (RM4-5) (BD Biosciences); PeCy7-conjugated anti-IgM (II/41); and PerCP-Cy5.5 conjugated antiCD21/CD35 (7E9) (BioLegend). Single-cell suspensions of freshly isolated thymus, spleen, peripheral lymph nodes (inguinal, axillary, and brachial), and total bone marrow cells of femur and tibia were subsequently incubated with anti-CD16/CD32 for 10 minutes, followed by staining with a combination of conjugated antibodies in FACS buffer (PBS $+4 \%$ heat-inactivated FCS + 2 mM EDTA) for 30 minutes. Before antibody staining, $250 \mu \mathrm{l}$ of freshly isolated blood was treated with heparin solution, and red blood cells were lysed with BD Pharm Lyse solution (BD Biosciences) according to the manufacturer's protocol. Stained cells were analyzed on a FACSCanto II Flow Cytometer (BD Biosciences) equipped with blue (488 nm), violet $(405 \mathrm{~nm})$, and red $(633 \mathrm{~nm})$ lasers. FACS data were statistically analyzed with FlowJo software (TreeStar Inc.).

Histopathology and immunohistochemistry. Tissue samples from the spleen, thymus, axillary lymph nodes, mesenteric lymph nodes, and intestine (including Peyer patches) were collected from WT $\left(S p n s 2^{+/+}, n=3\right)$ and Spns2 $2^{--}\left(\right.$Spns $\left.2^{--}, n=3\right)$ mice and fixed in $20 \%$ neutral phosphate-buffered formalin. Each paraffin-embedded tissue was cut into $4-\mu \mathrm{m}$ thickness and stained with H\&E for light microscopy.

For immunohistochemistry, paraffin was then removed from the sections and antigen retrieval was performed in $10 \mathrm{mM}$ citrate buffer ( $\mathrm{pH}$ 6.0) by placing the sections in a pressure cooker for 3 minutes. Endogenous 
peroxidase activity was blocked with $0.3 \% \mathrm{H}_{2} \mathrm{O}_{2}$ in methanol. The sections were exposed to $1 \% \mathrm{BSA}$ in PBS and were then incubated overnight at $4{ }^{\circ} \mathrm{C}$ with goat anti-CD3ع (M-20; Santa Cruz Biotechnology Inc.). Immune complexes were labeled with biotinylated anti-goat IgG and streptavidin alkaline phosphatase (Nichirei). The signals were visualized with a Vector Blue Alkaline Phosphatase Substrate Kit (Vector Laboratories). For double immunostaining, sections were sequentially incubated with rat anti-CD45R (BD Biosciences - Pharmingen). Immune complexes were detected with HRP-conjugated anti-rat IgG (simple stain Max-Po; Nichirei) and 3-amino-9-ethyl carbazole (AEC) substrate system (Lab Vision) for color development.

$S 1 P$ release from blood cells. Blood was collected from anesthetized WT $\left(\right.$ Spns $\left.2^{+/+}, n=4\right)$ and Spns2 $2^{-/-}\left(\right.$Spns $\left.2^{-/-}, n=4\right)$ mice via the inferior vena cava using heparinized syringes and transferred to tubes containing EDTA as an anticoagulant. Blood cells were separated from plasma by centrifugation at $1,200 \mathrm{~g}$ for 5 minutes at $4^{\circ} \mathrm{C}$ and washed twice with ice-cold PBS to remove plasma residues. The cells were resuspended in the ice-cold incubation buffer containing $20 \mathrm{mM}$ Hepes, pH 7.4, $138 \mathrm{mM} \mathrm{NaCl}, 3.3 \mathrm{mM} \mathrm{NaH}_{2} \mathrm{PO}_{4}$, $2.9 \mathrm{mM} \mathrm{KCl}, 1.0 \mathrm{mM} \mathrm{MgCl}, 1 \mathrm{mg} / \mathrm{ml}$ glucose, and $1 \%$ fatty acid-free bovine serum albumin at a cell density of $5 \times 10^{8}$ cells $/ \mathrm{ml}$. Then $500 \mu \mathrm{l}$ of blood cell suspensions $\left(2.5 \times 10^{8}\right.$ cells $)$ was incubated at $4^{\circ} \mathrm{C}$ or at $37^{\circ} \mathrm{C}$ for 90 minutes. After incubation, the cells were pelleted by centrifugation at $1,200 \mathrm{~g}$ for 5 minutes at $4^{\circ} \mathrm{C}$. The S1P levels in the supernatants were determined as described above. To quantify the total amount of S1P in the blood cells, cells were collected from $500 \mu \mathrm{l}$ of cell suspensions by centrifugation at $1,200 \mathrm{~g}$ for 5 minutes at $4^{\circ} \mathrm{C}$ and homogenized in $100 \mu \mathrm{l}$ of methanol.

Generation of bone marrow chimeras. Bone marrow chimeras were generated with $5 \times 10^{6}$ freshly isolated total bone marrow cells from femur and tibia of WT and Spns2 floxed mice (donor). Isolated cells were injected i.v. into lethally irradiated (900 cGY) Spns2-/- and Spns2-ECKO mice (host). Hematopoietic reconstitution of lymphoid organs of hosts by donor-derived cells was controlled 6 weeks after bone marrow transfer by genotyping of total bone marrow cells. Furthermore, lymphoid organs of reconstituted mice were FACS analyzed as described above.

In situ bybridization and immunohistochemistry on serial tissue sections. In situ hybridization and immunohistochemistry on serial tissue sections was performed by Genostaff. Briefly, the thymus, heart, lung, brain, and kidney of 8-week-old mice were dissected after perfusion, fixed with Tissue Fixative (Genostaff), and then embedded in paraffin by proprietary procedures and sectioned at $6 \mu \mathrm{m}$.

For in situ hybridization, tissue sections were de-waxed with xylene and rehydrated through an ethanol series and PBS. The sections were fixed with 4\% paraformaldehyde in PBS for 15 minutes and then washed with PBS. The sections were treated with $8 \mu \mathrm{g} / \mathrm{ml}$ Proteinase K in PBS for 30 minutes at $37^{\circ} \mathrm{C}$, washed with PBS, refixed with $4 \%$ paraformaldehyde in PBS, again washed with PBS, and placed in $0.2 \mathrm{~N} \mathrm{HCl}$ for 10 minutes. After washing with PBS, the sections were acetylated by incubation in $0.1 \mathrm{M}$ tri-ethanolamine- $\mathrm{HCl}, \mathrm{pH} 8.0,0.25 \%$ acetic anhydride for $10 \mathrm{~min}$ utes. After washing with PBS, the sections were dehydrated through a series of ethanol. The cDNA templates for Spns2 were 535-bp and 634-bp fragments corresponding to bases 1629-2163 and 2291-2924 of mouse Spns2 cDNA (GenBank NM_153060.2). Sense and antisense riboprobes for Spns 2 mRNA were synthesized using a digoxigenin RNA labeling kit (Roche) according to the manufacturer's protocol. Hybridization was performed with probes at concentrations of $300 \mathrm{ng} / \mathrm{ml}$ in the Probe Diluent-1 (Genostaff) at $60^{\circ} \mathrm{C}$ for 16 hours. After hybridization, the sections were washed in $5 \times \mathrm{HybriWash}$ (Genostaff), equal to $5 \times \mathrm{SSC}$, at $50^{\circ} \mathrm{C}$ for 20 minutes and then in $50 \%$ formamide, $2 \times$ HybriWash at $50^{\circ} \mathrm{C}$ for 20 minutes, followed by RNase treatment in $50 \mu \mathrm{g} / \mathrm{ml}$ RNase A in $10 \mathrm{mM}$ Tris- $\mathrm{HCl}, \mathrm{pH} 8.0,1 \mathrm{M} \mathrm{NaCl}$, and $1 \mathrm{mM}$ EDTA for 30 minutes at $37^{\circ} \mathrm{C}$.
Then the sections were washed twice with $2 \times$ HybriWash at $50^{\circ} \mathrm{C}$ for 20 minutes, twice with $2 \times$ HybriWash at $50^{\circ} \mathrm{C}$ for 20 minutes, and once with TBST ( $0.1 \%$ Tween 20 in TBS). After treatment with $0.5 \%$ blocking reagent (Roche) in TBST for 30 minutes, the sections were incubated with anti-DIG AP conjugate (Roche) diluted 1:1,000 with TBST for 2 hours at RT. The sections were washed twice with TBST and then incubated in $100 \mathrm{mM} \mathrm{NaCl}, 50 \mathrm{mM} \mathrm{MgCl}_{2}, 0.1 \%$ Tween 20, and $100 \mathrm{mM}$ Tris- $\mathrm{HCl}$, $\mathrm{pH}$ 9.5. Coloring reactions were performed with NBT/BCIP solution (Sigma-Aldrich) overnight and then washed with PBS. The sections were counterstained with Kernechtrot Stain Solution (Mutoh), dehydrated, and mounted with Malinol (DBS).

For immunohistochemistry, serial tissue sections were deparaffinized with xylene and rehydrated through an ethanol series and TBS. Endogenous peroxidase activity was blocked with $0.3 \% \mathrm{H}_{2} \mathrm{O}_{2}$ in methanol for 30 minutes. For CD31 staining, the sections were treated with Protein Block (Dako) and avidin/biotin blocking kit (Vector), and incubated with $0.1 \mu \mathrm{g} / \mathrm{ml}$ of anti-CD31 rabbit polyclonal antibody (Spring Bioscience) at $4{ }^{\circ} \mathrm{C}$ overnight. Immune complexes were labeled with biotin-conjugated goat anti-rabbit Ig (Dako) and peroxidase-conjugated streptavidin (Nichirei). For $\alpha$-SMA staining, sections were treated with Blocking Reagent A (Nichirei) and incubated with anti- $\alpha$-SMA mouse monoclonal antibody (Dako) at $4{ }^{\circ} \mathrm{C}$ overnight. The sections were then blocked with Blocking Reagent B (Nichirei) and incubated with Simple Stain Mouse MAX-PO (M) (Nichirei). Peroxidase activity was visualized by diaminobenzidine. The sections were counterstained with Mayer's hematoxylin, dehydrated, and mounted with Malinol (Muto).

Statistics. Data were analyzed using GraphPad Prism software (GraphPad Software Inc.). Statistical significance was determined using a 2-tailed MannWhitney $U$ test for paired samples or 1-way ANOVA and nonparametric tests for multiple groups. $P<0.05$ was considered statistically significant.

Study approval. All animal experiments were approved by the animal committee of the National Cerebral and Cardiovascular Center and performed according to the regulations of the National Cerebral and Cardiovascular Center.

\section{Acknowledgments}

We thank T.N. Sato and M. Yanagisawa (Nara Institute of Science and Technology and University of Texas Southwestern Medical Center, respectively) for Tie2Cre mice. We are also grateful to K. Hiratomi, W. Koeda, M. Sone, H. Yonekawa, and Y. Matsuura for technical assistance, and to K. Shioya for providing excellent animal facilities. This work was supported in part by Grants-inAid for Scientific Research on Innovative Areas, "Fluorescence Live Imaging” (No. 22113009 to S. Fukuhara and No. 22113007 to M. Ishii) and "Neuro-Vascular Wiring" (No. 22122003 to N. Mochizuki), of The Ministry of Education, Culture, Sports, Science, and Technology, Japan; and by grants from the Japan Society for the Promotion of Science (to S. Fukuhara, M. Ishii, and N. Mochizuki); the Ministry of Health, Labour, and Welfare of Japan (to N. Mochizuki); the Program for the Promotion of Fundamental Studies in Health Sciences of the National Institute of Biomedical Innovation (to S. Fukuhara and N. Mochizuki); a grant from the International Human Frontier Science Program (to M. Ishii); the Takeda Science Foundation (to M. Ishii and N. Mochizuki); the Mitsubishi Foundation (to N. Mochizuki); the Japan Cardiovascular Research Foundation (to S. Fukuhara); and an AstraZeneca research grant (to N. Mochizuki).

Received for publication August 30, 2011, and accepted in revised form January 30, 2012. 
Address correspondence to: Shigetomo Fukuhara or Naoki Mochizuki, Department of Cell Biology, National Cerebral and Cardiovascular Center Research Institute, 5-7-1 Fujishirodai, Suita, Osaka 565-8565, Japan. Phone: 81.6.6833.5012; Fax: 81.6.6835.5461; E-mail: fuku@ri.ncvc.go.jp (S. Fukuhara),

1. Chi H. Sphingosine-1-phosphate and immune regulation: trafficking and beyond. Trends Pharmacol Sci. 2011;32(1):16-24.

2. Cyster JG. Chemokines, sphingosine-1-phosphate, and cell migration in secondary lymphoid organs. Annu Rev Immunol. 2005;23:127-159.

3. Hla T. Physiological and pathological actions of sphingosine 1-phosphate. Semin Cell Dev Biol. 2004; 15(5):513-520.

4. Rivera J, Proia RL, Olivera A. The alliance of sphingosine-1-phosphate and its receptors in immunity. Nat Rev Immunol. 2008;8(10):753-763.

5. Spiegel S, Milstien S. The outs and the ins of sphingosine-1-phosphate in immunity. Nat Rev Immunol. 2011;11(6):403-415.

6. Alvarez SE, et al. Sphingosine-1-phosphate is a missing cofactor for the E3 ubiquitin ligase TRAF2. Nature. 2010;465(7301):1084-1088.

7. Allende ML, Dreier JL, Mandala S, Proia RL. Expression of the sphingosine 1-phosphate receptor, S1P1, on T-cells controls thymic emigration. J Biol Chem. 2004;279(15):15396-15401.

8. Matloubian M, et al. Lymphocyte egress from thymus and peripheral lymphoid organs is dependent on S1P receptor 1. Nature. 2004;427(6972):355-360.

9. Pappu R, et al. Promotion of lymphocyte egress into blood and lymph by distinct sources of sphingosine-1phosphate. Science. 2007;316(5822):295-298.

10. Schwab SR, Pereira JP, Matloubian M, Xu Y, Huang Y, Cyster JG. Lymphocyte sequestration through S1P lyase inhibition and disruption of S1P gradients. Science. 2005;309(5741):1735-1739.

11. Brinkmann V, et al. The immune modulator FTY720 targets sphingosine 1-phosphate receptors. J Biol Chem. 2002;277(24):21453-21457.

12. Graler MH, Goetzl EJ. The immunosuppressant FTY720 down-regulates sphingosine 1-phosphate G-protein-coupled receptors. FASEB J. 2004; 18(3):551-553.

13. Mandala S, et al. Alteration of lymphocyte trafficking by sphingosine-1-phosphate receptor agonists. Science. 2002;296(5566):346-349.

14. Brinkmann V, et al. Fingolimod (FTY720): discovery and development of an oral drug to treat multiple sclerosis. Nat Rev Drug Discov. 2010;9(11):883-897.

15. Allende ML, Tuymetova G, Lee BG, Bonifacino E, Wu YP, Proia RL. S1P1 receptor directs the release of immature B cells from bone marrow into blood. J Exp Med. 2010;207(5):1113-1124.

16. Pereira JP, Xu Y, Cyster JG. A role for S1P and S1P1 in immature-B cell egress from mouse bone marrow. PLoS One. 2010;5(2):e9277.

17. Schwab SR, Cyster JG. Finding a way out: lymphocyte egress from lymphoid organs. Nat Immunol. 2007; 8(12):1295-1301.

18. Breart B, et al. Lipid phosphate phosphatase 3 enables efficient thymic egress. J Exp Med. 2011; 208(6):1267-1278.

19. Zachariah MA, Cyster JG. Neural crest-derived pericytes promote egress of mature thymocytes at the corticomedullary junction. Science. 2010; 328(5982):1129-1135.

20. Pham TH, et al. Lymphatic endothelial cell sphingosine kinase activity is required for lymphocyte egress and lymphatic patterning. J Exp Med. 2010; 207(1):17-27.

21. Spiegel S, Milstien S. Functions of the multifaceted family of sphingosine kinases and some close relatives.

\section{J Biol Chem. 2007;282(4):2125-2129.}

22. Kim RH, Takabe K, Milstien S, Spiegel S. Export and functions of sphingosine-1-phosphate. Biochim Biophys Acta. 2009;1791(7):692-696.

23. Hanel P, Andreani P, Graler MH. Erythrocytes store and release sphingosine 1-phosphate in blood. FASEB J. 2007;21(4):1202-1209.

24. Kobayashi N, et al. Sphingosine 1-phosphate is released from the cytosol of rat platelets in a carriermediated manner. J Lipid Res. 2006;47(3):614-621.

25. Yang L, Yatomi Y, Miura Y, Satoh K, Ozaki Y. Metabolism and functional effects of sphingolipids in blood cells. Br J Haematol. 1999;107(2):282-293.

26. Yatomi Y, et al. Sphingosine 1-phosphate, a bioactive sphingolipid abundantly stored in platelets, is a normal constituent of human plasma and serum. J Biochem. 1997;121(5):969-973.

27. Ito $\mathrm{K}$, et al. Lack of sphingosine 1-phosphatedegrading enzymes in erythrocytes. Biochem Biophys Res Commun. 2007;357(1):212-217.

28. Olivera A, et al. The sphingosine kinase-sphingosine-1-phosphate axis is a determinant of mast cell function and anaphylaxis. Immunity. 2007; 26(3):287-297.

29. Kobayashi N, Kobayashi N, Yamaguchi A, Nishi T. Characterization of the ATP-dependent sphingosine 1-phosphate transporter in rat erythrocytes. J Biol Chem. 2009;284(32):21192-21200.

30. Mitra P, Oskeritzian CA, Payne SG, Beaven MA, Milstien S, Spiegel S. Role of ABCC1 in export of sphingosine-1-phosphate from mast cells. Proc Natl Acad Sci U S A. 2006;103(44):16394-16399.

31. Sato K, et al. Critical role of ABCA1 transporter in sphingosine 1-phosphate release from astrocytes. J Neurochem. 2007;103(6):2610-2619.

32. Takabe $\mathrm{K}$, et al. Estradiol induces export of sphingosine 1-phosphate from breast cancer cells via ABCC1 and ABCG2. J Biol Chem. 2010; 285(14):10477-10486.

33. Kawahara A, Nishi T, Hisano Y, Fukui H, Yamaguchi A, Mochizuki N. The sphingolipid transporter spns2 functions in migration of zebrafish myocardial precursors. Science. 2009;323(5913):524-527.

34. Osborne N, et al. The spinster homolog, two of hearts, is required for sphingosine 1-phosphate signaling in zebrafish. Curr Biol. 2008; 18(23):1882-1888.

35. Campbell JJ, Pan J, Butcher EC. Cutting edge: developmental switches in chemokine responses during $\mathrm{T}$ cell maturation. J Immunol. 1999;163(5):2353-2357.

36. Weinreich MA, Hogquist KA. Thymic emigration: when and how T cells leave home. J Immunol. 2008;181(4):2265-2270.

37. Ge Q, Chen WF. Phenotypic identification of the subgroups of murine T-cell receptor alphabeta+ CD4+ CD8- thymocytes and its implication in the late stage of thymocyte development. Immunology. 1999;97(4):665-671.

38. Tian T, Zhang J, Gao L, Qian XP, Chen WF. Heterogeneity within medullary-type TCR $\alpha \beta^{+} \mathrm{CD} 3^{+} \mathrm{CD} 4^{-} \mathrm{CD} 8^{+}$thymocytes in normal mouse thymus. Int Immunol. 2001;13(3):313-320.

39. Rosen H, Alfonso C, Surh CD, McHeyzer-Williams MG. Rapid induction of medullary thymocyte phenotypic maturation and egress inhibition by nanomolar sphingosine 1-phosphate receptor agonist. Proc Natl Acad Sci U S A. 2003; 100(19):10907-10912.
40. Argraves KM, Argraves WS. HDL serves as a S1P signaling platform mediating a multitude of cardiovascular effects. J Lipid Res. 2007;48(11):2325-2333.

41. Sato K, Okajima F. Role of sphingosine 1-phosphate in anti-atherogenic actions of high-density lipoprotein. World J Biol Chem. 2010;1(11):327-337.

42. Aoki S, et al. Sphingosine 1-phosphate-related metabolism in the blood vessel. J Biochem. 2005; 138(1):47-55

43. Lee YM, Venkataraman K, Hwang SI, Han DK, Hla T. A novel method to quantify sphingosine 1phosphate by immobilized metal affinity chromatography (IMAC). Prostaglandins Other Lipid Mediat. 2007;84(3-4):154-162.

44. Venkataraman K, et al. Vascular endothelium as a contributor of plasma sphingosine 1-phosphate. Circ Res. 2008;102(6):669-676.

45. Kisanuki YY, Hammer RE, Miyazaki J, Williams SC, Richardson JA, Yanagisawa M. Tie2-Cre transgenic mice: a new model for endothelial cell-lineage analysis in vivo. Dev Biol. 2001;230(2):230-242.

46. Schlaeger TM, et al. Uniform vascular-endothelialcell-specific gene expression in both embryonic and adult transgenic mice. Proc Natl Acad Sci US A. 1997; 94(7):3058-3063.

47. Takakura N, et al. A role for hematopoietic stem cells in promoting angiogenesis. Cell. 2000; 102(2):199-209.

48. Liu Y, et al. Edg-1, the G protein-coupled receptor for sphingosine-1-phosphate, is essential for vascular maturation. J Clin Invest. 2000;106(8):951-961.

49. Takada K, et al. Kruppel-like factor 2 is required for trafficking but not quiescence in postactivated $\mathrm{T}$ cells. J Immunol. 2011;186(2):775-783.

50. Nagasawa T. Microenvironmental niches in the bone marrow required for B-cell development. Nat Rev Immunol. 2006;6(2):107-116.

51. Osmond DG, Batten SJ. Genesis of B lymphocytes in the bone marrow: extravascular and intravascular localization of surface IgM-bearing cells in mouse bone marrow detected by electron-microscope radioautography after in vivo perfusion of 125I anti-IgM antibody. Am J Anat. 1984; 170(3):349-365.

52. Pereira JP, An J, Xu Y, Huang Y, Cyster JG. Cannabinoid receptor 2 mediates the retention of immature B cells in bone marrow sinusoids. Nat Immunol. 2009;10(4):403-411.

53. Yagi T, et al. A novel ES cell line, TT2, with high germline-differentiating potency. Anal Biochem. 1993; 214(1):70-76.

54. Zhang J, et al. Angiopoietin-1/Tie2 signal augments basal Notch signal controlling vascular quiescence by inducing delta-like 4 expression through AKTmediated activation of beta-catenin. J Biol Chem. 2011;286(10):8055-8066.

55. Fukuhara S, et al. Differential function of Tie2 at cell-cell contacts and cell-substratum contacts regulated by angiopoietin-1. Nat Cell Biol. 2008; 10(5):513-526.

56. Inoue A, Arima N, Ishiguro J, Prestwich GD, Arai H, Aoki J. LPA-producing enzyme PA-PLA(1)alpha regulates hair follicle development by modulating EGFR signalling. EMBO J. 2011;19(16):4248-4260.

57. Tanaka M, Kishi Y, Takanezawa Y, Kakehi Y, Aoki J, Arai H. Prostatic acid phosphatase degrades lysophosphatidic acid in seminal plasma. FEBS Lett. 2004;571(1-3):197-204. 